\title{
Engelli Yönetimi ile Tükenmişlik Arasındaki İlişkiye Yönelik Sağlık Yöneticilerinde Yapılan Bir Araştırma
}

\author{
DOI: $10.26466 /$ opus.585061 \\ * \\ $\underline{\text { Suzan Urgan* }}$ \\ *Dr., 19 Mayıs Üniversitesi, Bafra İşletme Fakültesi, Bafra / Samsun / Türkiye \\ E-Posta: suzan.urgan@omu.edu.tr \\ ORCID: 0000-0002-9280-4174
}

Öz

Bireyin kendi ihtiyaçların yerine getirirken bedensel, ruhsal, zihinsel ve sosyal kısıtlanma ile karşılaşması onun engelliliğiyle ifade edilmektedir. Engelli personel organizasyon içinde diğer sağlıkl personellerle beraber bir faaliyet yürütmektedir. Engelli personel kadar engelli yakın olan personel de organizasyon içinde yer almakta ve yönetimleri özellik isteyen bir unsura dönüşmektedir. Sağllk yöneticileri bulundukları sağllk işletmelerinde oldukça karmaşık bir yönetim süreci yürütmektedir. Bu yönetim yoğun strese yol açmakta, ruhsal ve fiziksel enerji yoksunluğuyla ifade edilen tükenmişliği de meydana getirdiği öngörülmektedir. Bu çalışmanın amacl, engelli ve engelli yakınına sahip personelin yönetimi esnasında yöneticilerde tükenmişlik görülüp görülmediğinin ortaya çıkarlmasına yöneliktir. Bunun için engelli ve engelli yakına sahip personel bulunduran kamu hastanelerinin poliklinik sorumluları ve yardımcılarına yarı yapılandırılmış görü̈sme tekniği uygulanmıştır. Örneklem grubu ildeki tüm kamu hastanelerinin poliklinik sorumlu ve sorumlu yardımcılarından oluşan 7 kişidir. İçerik analizi ile verilerin analiz edilmesiyle yöneticilerin bir bölümünde tükenmişlik belirtilerinden duyarsızlaşma, enerjinin tükenmesi ve yorgunluk bulgularına rastlanmıştır. Bununla beraber yöneticilerin büyük oranda tükenmişlik hissetmedikleri, engelli veya engelli yakına sahip personele empati yaparak işlerini kolaylaştırmaya çalışıłıları ortaya çıkarılmıştır. Elde edilen bulgular, engelli ve engelli yakına sahip personel yönetiminin, örgütsel davranış ile yönetim ve organizasyon alanında değerlendirilmesi gereken ayrı bir kavram olduğunu ortaya çıkarmaktadır.

Anahtar Kelimeler: Engelli Yönetimi, Duygusal Tükenme, Duyarsızlaşma, Tükenmişlik, Sağlık Yönetimi 


\title{
A Research on Health Administrators Regarding The Relation Between Management of The Disabled and Burnout
}

\begin{abstract}
While fulfilling own needs, an individual's facing physical, spiritual, mental and social restraints is stated with his/her disability. Disabled staff carry out activities together with other personnel in the organization. As much as disabled staff, there are also personnel having kinship with disabled people in the organization, and their management turns into factor requiring specialty. Health administrators conduct a quite complex management process in their health enterprises. Beside causing an intense stress, it is envisaged that this management forms burnout expressed with the deficiency of spiritual and physical energy. This study tries to reveal the burnout status of the managers of the disabled staff and the personnel having kinship with disabled people in the management process. For this, semi-structured interview technique has been applied to polyclinic curators and assistants of public hospitals, which have a large number of disabled staff and personnel having kinship with disabled people. The sample group consisted of 7 people in charge of polyclinics in all public hospitals in the province. As a result of analyzing the data with content analysis, signs of depersonalization, depletion of energy and fatigue have been found in some managers. In addition, managers do not feel much burnout and try to facilitate the work of disabled staff and personnel having kinship with disabled people, by empathizing. The findings obtained ascertain that the management of disabled staff and personnel having kinship with disabled people is a specific subject needed to be evaluated in the context of organizational behavior, and management and organization.
\end{abstract}

Keywords: Disability Management, Emotional Exhaustion, Desensitization, Burnout, Health Management 


\section{Giriş}

Sağlık işletmeleri hizmet alan ve hizmet veren grup açısından değerlendirildiğinde oldukça karmaşık bir yapıda olduğu görülmektedir. Bu karmaşık yapıda hizmet sunan personel arasında engelli personel ve engelli yakına sahip personel yer almaktadır. Engellilik bir şey yapma yetisi olamamak anlamına gelmektedir. Engelli bireyler bedensel ya da zihinsel açıdan normal olmayan şekilde eksiklik ya da yetersizlikle normal uğraşlara katılamayan insan grubu olarak ifade edilmektedir (Thomas, 2011).

Engeli olan ve engelli yakını olan personelin oldukça yoğun bir şekilde bulunduğu sağlık işletmelerinde bu personelin yönetimi de bir takım zorlukları beraberinde getirmektedir. Hassas bir yapıya sahip bu bireylerle, yoğun bir çalışma düzeni içinde bir faaliyet yürütülmek durumunda kalınmaktadır. Yöneticilerin daha dikkatli davranması gereken bu personel grubu, onları psikolojik olarak etkilemektedir. Bazen stres kaynağı olarak yöneticilerde tükenmişliğe neden olduğu var sayılmaktadır. Tükenmişlik, stres sonucu bireyin işle ilişkin tutum ve hareketlerinde gözlenen değişimler, fiziksel, duygusal yoğunluk ve tasa ile kendini gösteren bir durum olarak ifade edilmektedir (Özgüven, 2016). İlgili sağlık yöneticileri, bir taraftan sağlığı bozulmuş olan insanlara hizmet vermeye çalışarak bir hizmet yürütmektedir. Bir taraftan da sağlık açısından engelli olan ya da engelli bir yakına sahip olan bireylerin hizmet verme sürecine katılmasıyla oluşan hassas bir dengeyi yürütmeye çalışmaktadır.

$\mathrm{Bu}$ çalışma ile engelli ve engelli yakınlarının yönetiminde yer alan sağlık yöneticilerinin, yönetim sürecinde, tükenmişlikle sonuçlanan duygu durumlarının meydana gelip gelmediği ortaya konulmaya çalışılacaktır. Sağlık işletmelerinde, engelli ve engelli yakınlarına sahip personel, nöbet tutamamaları nedeniyle poliklinik gruplarında istihdam edilmektedir. Konunun amacına uygun olacağı öngörüsünden yola çıkarak, araştırma, poliklinik sorumlu ve sorumlu yardımcılarıyla yapılmıştır. Fenemonolojik çalışma deseni çerçevesinde yarı yapılandırılmış görüşme tekniği soruları hazırlanarak mülakatlar yapılmıştır. Görüşme formu ana çalışma sorusunu takip eden iki alt kategoriden oluşmaktadır. Birinci bölümde poliklinik yöneticilerinin demografik özelliklerini ortaya çıkarmaya yarayan sorular vardır. İkinci 
bölümünde yöneticilerin engelli ve engelli yakına sahip personelin yönetimi esnasında,içinde bulundukları duygu durumunu ve uyguladıkları stratejileri içeren ana soru ve bunun alt gruplardan oluşan açık uçlu sorular yer almaktadır. Literatür değerlendirildiğinde engelli ve engelli yakına sahip personelin yönetimi ile ilgili alanın boş olduğu görülmektedir. Kendi engelli ve engelli yakına sahip personel sağlıklı personellerin duygu durumu ve düşüncesinde olamamaktadır. Bu gruba giren personeli yönetmek özellik isteyen bir durum olarak değerlendirilmektedir. Yapılan çalışmanın bir benzeri yoktur. Dolayısıyla örgütsel davranış ile yönetim ve organizasyon alanına engelli yönetimi kavramının ilave edilmesinin faydalı olacağı düşünülmektedir.

\section{Engelli Yönetimi}

Engellilik kavramı sakatlık, yetersizlik, zedelenme ve özürlülük kavramlarıyla beraber kullanılan bir kavram olmaktadır. Kavram, yetersizlik ve zedelenme ile daha ilgili olarak ifade edilmektedir. Zedelenme kavramı bireyin fonksiyonel özelliklerinde geçici ya da daimi olarak bir kayıp olması durumudur. Yetersizlik kavramı ise bireyin, meydana gelen zedelenme sonucunda yaşamını idame ettirmesinde karşılaştığ sonucundaki yetersizliği ile ifade edilmektedir (Baş, 2016). Sakatlık, yeti yitimi anlamından hareketle bedensel ve zihinsel olarak normal faaliyet gösteremeyerek toplumsal faaliyetlere katılamama durumu olmaktadır. Bireyin kendi yeti yitimi yanında, yeti yitimi olmayanların gerçekleştirmiş olduğu kısitlamalar ve engellemeler de sakatlığa neden olan durum olarak ifade edilmektedir (Thomas, 2011). Başka bir tanımlama ile sakatlık, bedensel, zihinsel, duygusal ve sosyal yönden fonksiyon yerine getiremeyecek şekilde organ yokluğu ve ya bozukluğudur (Usta, 1992). Engelliğin tıbbi yönden ele alınması kadar sosyal ve kültürel boyutuyla da ele alınması önem arz etmektedir. Birey biyolojik olarak normal yaşamın dışında kalarak, sosyal bir sistem içerisinde engellenmeyle karşılaşmaktadır. Böylece, bireyin ihtiyaçları karşılanamamakta ve bağımsızlığı sağlanamamaktadır (Burcu, 2007).

Özürlülük anlamında yapılan tanımlamalar ortak bir paydada birleştirildiğinde özürlülüğü anlama ve tanımlama süreçlerini birleştiren bir sınıflandırma sistemi ortaya çımaktadır. -İnternational Classificiation 
of Impairments, Disabilities and Handicaps- Sakatlık, Özürlülük ve Engelliliğin Uluslararası Sınıflandırması özürlülüğü yetersizlik ve engellilik olarak sınıflamaktadır. Bununla beraber Dünya Sağlık Örgütünün yaklaşımıyla özürlülük sadece kişisel anlamda ele alınmamaktadır. Kişisel yaklaşımdan ziyade, onlaradayatılan sosyal davranışlar ve insanlar tarafından oluşturulmuş çevresel faktörler sonucu oluşmaktadır (Erdugan, 2010).

Engelli bireyler günlük yaşam içinde çok görülmeseler de sayıları az değildir. Dünya Sağlık Örgütü'nün 2011 rakamlarına göre engelli bireyler tüm dünya nüfusunun \%15'ini oluşturmaktadır. Aynı şekilde Türkiye'de 2002'de yapılan çalışma nüfusun \%13'ünün engelli bireylerden oluştuğunu göstermektedir (Yelpaze ve Türküm, 2018, s.169).

Engelli bireylere yönelik yapılan çalışmalar incelendiğinde, onların sosyal yaşam içerisinde günlük hayatlarını kolaylaştırıcı önlemlerin alındığı çalışmalar dikkat çekicidir (Baş, 2016). Bu anlamda Türkiye'de ve dünyada engelli çalışanların istihdam edilmesi özel kanunlarla belirlenmiştir. Yönetim ve örgütsel davranış literatürü incelendiğinde engelli yönetiminde yeterli çalışmaya rastlanmamaktadır. Ancak engelli personelin ve engelli yakını olan personelin insan kaynakları içerisinde yönetimi özellikli bir konu olmaktadır. Pratikte bunun zorluğu görülmektedir. Yapılan çalışmalar, engelli bireylerin, sosyolojik açıdan toplumdaki yerlerini ifade ederek onların sorunlarına odaklanılan araştırmalarla sınırlıdır (Burcu, 2015). Bunlardan biri engelliliği tarihsel açıdan ele alarak kuram olarak incelemektedir (Thomas, 2011). Özürlülüğe dayalı ayrımcılık da bazı araştırmacılar tarafından ele alınmış, dışlanmanın şekli ve ölçüm çalışmaları yapılarak mücadele yöntemleri ortaya konulmuştur (Kökten ve Erdoğan, 2014; Akdoğan vd., 2010).

Engelli ve engelli yakını olan bireylerin örgütsel alan içinde yönetimi standart bir prosedürün izlenmesi ile yapılabilecek bir yönetimin dişında kalmaktadır. Onların mevcut durumlarının değişebilir niteliği ve hassasiyetleri yöneticileri ile aralarında farklı diyalogların oluşmasına neden olmaktadır. Özellikle, belirli bir hizmeti ya da üretimi ortaya çıkarabilmek için bir sistemi yöneten yönetici, engelli yönetiminde bu hassasiyeti göstermek için ayrı bir çaba sarf etmektedir. 


\section{Tükenmişlik}

Organizasyon içerisinde faaliyet göstermekte olan birey, zaman zaman mevcut koşullara uyum sağlayamama sonucu, psikolojik olarak ortaya çıkan ve sağlığını olumsuz etkileyen durumlarla karşılaşmaktadır. Organizasyon içinden ve dışından oluşan stres kaynakları bireye baskı uygulamaktadır. Bu baskı sonucunda bireyin yaşamış olduğu duygu durumlardan biri de tükenmişlik hissidir.

Tükenmişlik kavramının en genel tanımı enerji, güç ya da kaynakların talep yoğunluğu nedeniyle bitmesi, yorgunluk hissi ve başarısızlıkla karşılaşmaktır. İşe ait sürekli stres kaynaklarının bireyde oluşturduğu ruhsal ve fiziksel enerji yoksunluğudur (Dalkılıç, 2014). İlk kez 1974 yılında Freudengerger sağlık çalışanları üzerinde yapmış olduğu araştırma sonucunda tükenmişlik sendromunu literatürde kullanmıştır. Bu çalışmaya göre tükenmişlik sağlık çalışanlarında görülen yorgunluk ve hayal kırıklığı sonucunda yaptıkları işten vazgeçme olarak tanımlanmaktadır (Gündüz, 2017). Maslach ve diğerlerinin (1996) yapmış olduğu çalışmalarda bireyle diğer çalışanlar arasındaki ilişkilerin giderek zayıflaması sonucu duygusal durumlarındaki bozulma ve kişisel başarıdaki azalmayı ifade etmektedir (Schaufeli vd., 2009). Tükenmişlik sendromunda çalışanlar işlerine olan bağlılıklarını yitirmekte ve giderek örgütten uzaklaşmaya başladıkları bir süreç yaşamaktadır (Riggio vd., 2014).

Bireyler örgütsel yaşam içerisinde karşılaştıkları stres kaynaklarına dayanabilme güçlerinde farklılaşmaktadır. Stres kaynaklarının zaman içerisinde artmasıyla yoğun stres, yorgunluk ve bitkinlik, engellenmişlik, suçluluk ve çaresizlik hisleri birbirini izlemekte, son basamakta tükenmişlik kendini göstermektedir. Tükenme dönemi, duygusal tükenme, duyarsızlaşma ve yeterliliğin azalması süreçlerini içeren üç boyuttan oluşmaktadır (Solmuş, 2004).

Duygusal tükenmişlik, bireyin diğer bireylerle iletişimi esnasında, karşılaşmış olduğu psikolojik ve duygusal taleplere karşılık verebilme zorluğuyla kendini göstermektedir. Bazen taleplerin aşırılığı bireyin karşılama gücünü aşmaktadır (Özgüven, 2016). Duyarsızlaşmada, birey, faaliyetleriyle hizmet sunduğu kişilere karşı duygusal empati yapmaktan uzaklaşarak duygusuzlaşmaktadır (Arı ve Bal). Yeterliliğin azalması 
boyutunda ise birey kendisini yetersiz hissetmekte ve başarı düzeyi düşmektedir (Leiter ve Maslach, 1988).

Hizmet sektörü içinde özellikle sağlık çalışanlarında tükenmişlik oldukça sık görülmektedir (Erdoğan ve İraz, 2019). Sağlık personeli arasında tükenmişlik seviyesinin yüksekliğinin nedenleri arasında aşırı iş yükü, çalışma sürelerinin belirsizliği, yaptıkları işlere karşı aldıkları ücretin yetersizliği, işyeri baskıları, örgüt iklimi, hiyerarşik düzen içerisindeki yerleri ve motivasyon eksiklikleri gibi faktörler etkili olmaktadır. Tüm bu nedenlerden dolayı stres yükleri artmaktadır (Eriş vd., 2017, s.336). Karşılaştıkları stres yoğunluğu onunla başa çıkma eşiğinin üstünde gerçekleşmektedir. Hizmet verilen grup açısından hastalar, hasta aileleri ve sürekli olumsuz bir duygulanım durumu içinde bulunan hasta yakınları çalışan personeli etkilemektedir (Çam ve Engin: 2017, s.502).

Sağlık çalışanları arasında tükenmişlik seviyelerini ortaya koyan çalışmalar literatürde mevcuttur. Geniş katılımcı sayısıyla yapılan çalışmalara bakıldığında bu çalışmalardan biri 7 coğrafi bölge ve 11 ili kapsayan sağlık çalışanları tükenmişlik durumu araştırmasıdır. Bu araştırma sonucuna göre Türkiye'deki sağlık çalışanları arasında duygusal tükenme 23,96, duyarsızlaşma 9,51 ve kişisel başarı ise 28,90 puan olarak ortaya çıkarılmıştır. Toplam tükenmişlik puanı ise 52,19 olarak gerçekleşmiştir (Sağ-Sen Sendikası, Türkiye'de Sağlık Çalışanları Tükenmişlik Araştırması Sonuçları, 2012). Dünya ölçeğinde. Amerika'da yapılan çalışmalara gore, Amerika'da çalışan doktorların yarısında, Almanya ve İngiltere'deki doktorların \%27'sinde tükenmişlik belirtileri görülmüştür (Sandıkçı, 2017, s.63).

Önemli bir hizmeti yürütmekte olan sağlık çalışanlarının tükenmişlikle mücadele etmesi önem teşkil etmektedir. Çünkü tükenmişlik bir yerde işyeri hastalığı olarak değerlendirilmektedir. Bu iyileştirme çabaları bireysel ve örgüt bazında ele alınmaktadır. Hollanda, İngiltere, Kanada, Finlandiya ve Norveç'te yapılan 25 ayrı çalışma sonucunda bireysel iyileştirme yerine örgütsel iyileştirmelerin daha etkili olduğu sonucuna varılmıştır (Sandıkçı, 2017, s.63). 


\section{Yöntem}

Araştırma, poliklinik yöneticilerinin, kendi engelli ve engelli yakını olan çalışanların yönetimi esnasında hissetmiş oldukları duygu ve içinde bulundukları durumla ilgili olarak tükenmişlik durumunungelişip gelişmediğini ortaya koymaya yönelik nitel bir çalışmadır. Çalışmada fenemonolojik yöntem modeli kullanılmıştır. Fenemonolojik yöntem içinde yaşadığımız ancak ayrıntılı ve derin bir anlayışa sahip olamadığımız olguları ortaya çıkarmaya yarayan olgu bilimidir $(\mathrm{Ku}-$ rubacak, 2017'den akt. Urgan vd., 2018). Nitel araştırma yöntemlerinden biri olarak amacı genel olarak araştırmaya katılan katılımcıların araştırma konusu ile ilgili algı ve deneyimlerinden yola çıkarak bir genellemeye gitmektir. Araştırma konusu katılımcıların görüş açılarından ele alınarak deneklerin bu görüşleri nasıl ve neden oluşturdukları anlaşılmaya çalışılmaktadır (Gürbüz ve Şahin, 2014). Bu araştırma, evren ve örneklem açısından değerlendirildiğinde, nitel araştırma yöntemlerinden fenemonolojik yöntemin kullanılmasıyla gerekli verinin elde edilebilmesi açısından uygun olduğu var sayılmaktadır.

\section{Araştırmada Katılımo Grup}

Araştırmanın evrenini Eskişehir' de kamu hastanelerinde çalışmakta olan sağlık yöneticileri oluşturmaktadır. Bu sağlık yöneticileri arasındaki örneklem grubu, sağlık çalışanları arasında en çok engelli ve engelli yakınına sahip personelin istihdam edildiği yerde çalışmakta olan poliklinik yöneticileri oluşturmaktadır. Engelli ve engelli yakınının yönetiminden direkt sorumlu olan poliklinik sorumluları ve yardımcilarının konunun amacına uygun olacağı düşüncesinden hareket edilerek örneklem grubu seçilmiştir. Bu amaçla ilin tüm kamu hastanelerinin poliklinik sorumluları ve yardımcılarını içeren 7 sağlık çalışanı ile görüşme gerçekleştirilmiştir. Eskişehir ilinde tüm kamu hastanelerinde poliklinik hizmeti sunan 293 hemşire ve sağlık memuru bulunmaktadır. Bunlardan 51 çalışan kendisi engelli veya engelli yakına sahiptir. 


\section{Veri Toplama Araçları}

Araştırma için yarı yapılandırılmış görüşme tekniği örneği hazırlanarak katılımcılara yöneltilmiştir. Bu amaçla hazırlanan sorular ana araştırma sorusu ve görüşme soruları olarak iki ana kategoriye ayrılmaktadır. Ana araştırma sorusu engelli ve engelli yakınına sahip personelin yönetimi esnasında genel olarak içinde bulundukları duygu durumunu ifade eden sorudur. Görüşme formunun birinci kısmı çalışmaya katılanların demografik özelliklerini ifade eden sorulardan oluşmaktadır. İkinci kısım ise yöneticilerin engelli ve engelli yakınları olan çalışanların yönetimi esnasında hissettikleri ve kullandıkları stratejileri ifade eden alt grup sorulardan oluşmaktadır.

\section{Verilerin Analizi}

Nitel veri analizi, keşifsel bir süreç içermektedir. Bu süreçte araştırma verileri düzenlenmekte, tasnif edilmekte, sentezlenmekte, olgular arasındaki örüntüler ortaya çıkarılmakta ve kavramlara ulaşılmaktadır (Gürbüz ve Şahin, 2014, s.425). Araştırmada verilerin analizi nitel veri analizlerinden içerik analizi ile gerçekleştirilmiştir. İçerik analizinde görüşmecilerden alınan veriler deşifre edilmektedir. Deşifre edilen verilerden genellemeye gidilerek bir kavram ortaya çıkarılmaya çalışılmaktadır. İçerik analizinde görüşmecilerden alınan veriler deşifre edilmektedir. Deşifre edilen verilerden genellemeye gidilerek bir kavram ortaya çıkarılmaya çalışılmaktadır (Yıldırım ve Şimşek, 2006). Bu amaçla katılımcıların vermiş oldukları cevaplar katılımcılara birer kod verilerek çözümlenmiştir. Bu çözümleme ile cevaplar sayısallaştırılarak kodlanmıştır. Kodlama sonucu benzer cevaplar kümelenerek bir tema ortaya çıkarılmış ve yorumlanmıştır. İçerik analizinin güvenirliliğini belirlemede araştırmacılar arası güvenirlilik ve zaman açısından güvenirlilik olarak iki kıstas söz konusu olmaktadır. Bunlar da kodlamaların doğru yapılması ve kodlama kategorilerinin açık ve objektif olmasına dayanmaktadır (Potter ve LewineDonnestein, 1999). Çalışmada bu niteliklerden hareket edilerek kodlamaların açık ve anlaşılır olmasına dikkat edildi. İçerik analizlerinin geçerlilik açısından değerlendirilmesinde de iki unsur önemli olmaktadır. Birincisi zaman içerisinde değişmezliği ifade eden sosyal geçerliliktir. İkinci unsur 
ise görünüş geçerliliğidir. Görünüş geçerliliği ortak geçerlilik olarak da ifade edilmektedir (Krippendorf, 2004, s.314). İkinci unsurun dikkate alınmasıyla, araştırma bulguları akla uygun ve mantıklı olarak değerlendirilmesi geçerliliğin kriteri olmaktadır. Buradan hareketle çalışmada bulguların tutarlılığını ölçmek için kodlanmış olan kavramların kendi aralarında ve çalışmanın bütünüyle anlamlı bir bütün oluşturup oluşturmadığına bakılmıştır. Araştırmanın dış geçerliliği için daha önce yapılan çalışmaların sonuçlarına göre değerlendirme yapılmıştır. Ayrıca araştırma bulguları katılımcılarla paylaşılmış ve değerlendirilmeye gidilmiştir.

\section{Bulgular}

Aşağıdaki tabloda sağlık yöneticilerinin demografik bulguları verilmiştir.

Tablo 1. Katılımcilarn demografik durumu

\begin{tabular}{|c|c|c|c|c|c|c|c|}
\hline Katılımcılar & S1 & S2 & S3 & S4 & S5 & S6 & S7 \\
\hline Meslek & Hemşire & $\begin{array}{l}\text { Sağlık } \\
\text { Memuru }\end{array}$ & Hemşire & Hemşire & Ebe & Hemşire & Hemşire \\
\hline Yaş & 38 & 39 & 37 & 38 & 52 & 39 & 41 \\
\hline $\begin{array}{l}\text { Eğitim } \\
\text { Durumu }\end{array}$ & Ön Lisans & $\begin{array}{l}\text { Yüksek } \\
\text { Lisans }\end{array}$ & $\begin{array}{l}\text { Yüksek } \\
\text { Lisans }\end{array}$ & Lisans & $\begin{array}{l}\text { Ön } \\
\text { Lisans }\end{array}$ & $\begin{array}{l}\text { Yüksek } \\
\text { Lisans }\end{array}$ & Lisans \\
\hline $\begin{array}{l}\text { Mesleki } \\
\text { Tecrübe }\end{array}$ & 15 & 21 & 17 & 13 & 35 & 12 & 21 \\
\hline Medeni Hali & Evli & Evli & Evli & Evli & Evli & Evli & Evli \\
\hline
\end{tabular}

Sağlık yöneticisi katılımclara S1'den S7'e kadar birer kod verilmiştir. Görüşme formundaki sorulara verilen cevaplara göre, engelli ve engelli yakınlara sahip çalışanların yönetiminde neler hissedildiğine dair bulgular değerlendirilmiştir. Sağlık yöneticilerinin verdikleri cevaplara göre aşağıdaki sonuçlar ortaya çıkmıştır:

- Yönetim sürecinde yorgunluk, enerjinin tükenmesi, yıpranmış hissetme, engellenmiş hissetme, onları suçlama, onlarla çalışmak istememe, çaresiz, ümitsiz ve kapana kısılmış hissi: S3

- Onlara karşı duyarsızlaşma, onlarla alay etme, küçümseme, onlara karşı katı olma, herhangi bir duygu hissetmeme, kayıtsız kalma ve iletişim kurmaktan kaçma: S5 
- Onları yönetme sürecinde karşılaşılan problemlerde alternatif geliştirme: S2, S3, S6, S7

- Daha önce de bu tür problemlerle karşılaştığı için üstesinden gelme:S2, S4, S7

- Kendi soğukkanlılıklarını koruyarak sakin bir şekilde çözüm bulma: S1, S2, S4, S7

Engelli ve engelli yakınları olan çalışanların yönetimi sürecindeki stratejilere ait bulguların değerlendirilmesinde aşağıdaki bulgular ortaya çıkmıştır:

- $\quad$ Onlara empati yapma: S1, S2, S3, S4, S5, S6, S7

- $\quad$ İş odaklı davranma: S3, S5, S6

- $\quad$ Prosedürü yerine getirme: S3, S5, S6.

Kodlanarak ortaya çıkarılmış kavramlar değerlendirildiğinde engelli ve engelli yakınları olan çalışanların yönetim sürecinde karşılaşılan problemlere çözüm için alternatif geliştirildiği ortaya çıkmaktadır $f(4)$. Hastalara hizmet verme sürecinde, hizmeti veren kişilerin engelli ve engelli yakını olmasıyla ortaya çıkan problemlerde yöneticiler soğukkanlılıklarını koruyabilmektedir $\mathrm{f}(4)$. Bu problemlerin çözümü için daha önceki tecrübelerden faydalanılmaktadır $\mathrm{f}(3)$. Tüm bunların yanında ilgili yönetim sürecinde kendini çaresiz, ümitsiz hisseden ve enerjisinin tükendiğini ifade eden ve onlara karşı duyarsızlı̆̆ı alternatif olarak gören yönetici de görülmektedir $f(1) f(1)$.

Yine kodlanan kavramlar incelendiğinde engelli ve engelli yakınına sahip personelin yönetim sürecinde onlara karşı empati yapmanın dikkate değer olduğu görülmektedir f(7). Hatta duyarsız ve çaresiz olan yöneticiler de empati yapmaya çalışmaktadır. Çalışandan ziyade işe odaklanan $f(3)$ ve belirli prosedürü yerine getiren yönetici de başa baş görünmektedir $\mathrm{f}(3)$.

Sağlık yöneticileri bu süreçte empati yeteneklerini kendi cümleleriyle aşağıdaki gibi ifade etmektedir:

"Bu gün bir engelimiz olmasa da, her insan potansiyel bir engelli olabileceği düşüncesiyle hareket etmekteyim. Empati yaparak çalışıyorum. Engelli personelin engellerini görmezden gelme yerine daha fazla nasıl yardımcı olabilirim diye düşünmekteyim" S(1). "Sorumluluğum altındaki engelli çalışanlarımıza fiziksel yeterliliği-yetersizliği orantısında işler vermeye çalışırım. Aynı zamanda birlikte çalışacağı ekip 
arkadaşlarını da yeterince empati yapabilecek kapasitede ve toleransta olması gerekir ki, bu ekibi de ayarlamak durumundayım. Mesleğimiz, hizmet sektöründe insana hizmet vermek olduğu için, insan odaklı hareket etmekteyiz. Engelli çalışanlarımız için en iyisini düşünsek de hizmet verdiğimiz popülasyonun ön yargılı, sabırsız ve kaba yaklaşım ve söylemlerinden de engelli çalışanlarımızı korumak oldukça zor ve yıpratıcı" S(7). "Engelli personelin sağlık personeli olarak değil de idari hizmetlerde çalışmasını öneririm. Başka kurumlara geçişleri sağlanabilir. Sağlık sektörü zaten stresli ve yoğun çalışılan yerler" S(3).

\section{Sonuç}

Yapılan çalışma ile sağlık yöneticilerinde, engelli ve engelli yakını olan personel yönetimi ile kendi etkilenme düzeyleri arasındaki ilişki ortaya konulmaya çalışıldı. Yapılan mülakatlar ve yarı yapılandırılmış görüşme soruları değerlendirildiğinde, yöneticilerin büyük oranda engelli ve engelli yakına sahip personel yönetiminde kendi duygusal durumlarını korudukları sonucu ortaya çıkarıldı. Ancak iki yöneticinin tükenmişliği ifade eden duygu durumuna sahip olduğu görüldü. Bu yöneticiler onlarla çalışmayı zor bulmakta, kendilerini çaresiz, yıpranmış ve yorgun hissederek onlara karşı duyarsızlık hissi geliştirmiştir. Ayrıca onlarla iletişim kurmak istememektedir. Özellikle yaş olarak en büyük ve en küçük yöneticide tükenmişlik belirtileri vardır.

Araştırmanın başka bir sonucu sağlık yöneticilerinin hepsinin bu yönetim sürecinde engelli ve engelli yakını olan personele empati yapmaya çalışmasıdır. Bununla beraber yöneticilerin ortalama yarısı profesyonel bir şekilde iş odaklı davranarak prosedürü yerine getirmeyi strateji olarak benimsemektedir.

Kendi engelli ve engelli yakına sahip personel yönetimi konusunda literatürde yeterli çalışmaya rastlanmamıştır. Bununla beraber, yapılan çalışmalardan biri özel eğitim okulunda öğretmenlik yapan çalışma grubunu içermektedir. Bu çalışmada özel eğitim alan öğrencilere eğitim vermekte olan öğretmenlerin, duygusal tükenme ve duyarsızlaşma belirtileri gösterdikleri ortaya çıarılmıştır (Şahin ve Şahin, 2012). Zihinsel engelli öğrencilere eğitim veren öğretmenlerde tükenmişlik ve duyarsızlaşma boyutu hem bayan hem erkek öğretmenlerde görülmüştür. Ancak erkek 
öğretmenlerde daha yüksek olduğu tespit edilmiştir. Aynı çalışmada üstlerinden takdir görmeyen öğretmenlerin duygusal tükenme ve duyarsızlaşma puanları takdir gören öğretmenlerden daha fazla olduğu tespit edilmiştir (Girgin ve Baysal, 2005). Engelli ve yaşlı bakım personelinin tükenmişlik seviyesi ve çalışma kalitesi algısında hizmet içi eğitimin fark yaratan bir değişken olduğu bulgusu da yapılan başka bir çalışmanın sonucudur (Başol ve Sağlam, 2018).

Yapılan çalışma ile oldukça karmaşık bir sistem içinde hasta ve hasta yakınlarına hizmet sunulan sağlık sektöründe, yöneticilerin durumu farklı bir açıdan ele alınmıştır. Bu yöneticilerdeki, engelli ve engelli yakını bulunan personel ile oluşan yönetim sürecinde, tükenmişlik durumu incelenmesinde, onların ilgili personellere empati yaptıkları ortaya çıkarıldı. Bununla beraber,bazı yöneticiler empati yaparak engelli ve engelli yakına sahip personele uygun davranışı göstermeye çalışsalar da kendilerinde tükenmişlik belirtileri görülmüştür.

Elde edilen bulgular yapılan çalışmalarla kıyaslandı̆̆ında engellilere verilen hizmet kapsamında değerlendirilmesi uygun olmaktadır.Literatürde bulunan çalışmalar daha çok hizmet veren ve alan grupla ilişkilendirilerek yapılan çalışmaları içermektedir. Bu çalışmalarla da, hizmet sunumu sürecinde çalışanlarda tükenmişlik belirtileri görülmesi bakımından aynı paydada birleşilmektedir.

Yapılan çalışma sonucunda 7 sağlık yöneticisinin 2'sinde tükenmişlik belirtileri görülmesi oldukça yüksek olarak değerlendirilmektedir. Yukarıda da ifade edilen oldukça karmaşık bir süreci yönetmekte olan sağlık yöneticilerinin işi biraz daha zorlaşmaktadır. Engelli personel ve engelli yakına sahip personel diğer çalışanlara göre daha hassas bir yapıda olmaktadır. Dolayısıyla onlarla sağlıklı bir iletişim kurularak vermiş oldukları hizmeti değerlendirmek önem teşkil etmektedir.

Çalışma hayatının oldukça önemli bir bölümünde engelli personel ve engelli yakına sahip personel istihdam edilmektedir. Bundan sonraki çalışmalar için araştırmacıların farklı evrenler ve örneklem grubunda engelli yönetimi çalışması yapması, çalışmaya başka bir açıdan bakılarak anlaşılmasını kolaylaştıracaktır. Bu konu engelli yönetimi kapsamında literatürde yerini alması gereken önemli bir konu olarak değerlendirilmektedir. 


\title{
EXTENDED ABSTRACT
}

\section{A Research on Health Administrators Regarding The Relation Between Management of The Disabled and Burnout}

\author{
Suzan Urgan
}

Samsun 19 Mayıs University

When healthcare organizations are evaluated in terms of groups that get and/or provide service, it has seen that they have a very sophisticated structure. Disabled staff and the personnel having a disabled relative are among the personnel providing service in this sophisticated structure. Disability means the condition of being unable to perform. Disabled individuals are a group of people who are unable to participate usual activities due to the physical or mental disorders or inabilities (Thomas, 2011).

In these healthcare organizations, whose personnel predominantly are disabled or have a disabled relative, management is a challenging task. Organizations needs to carry out activities in an intense working order with these sensitive individuals. This personnel that managers need to pay attention affects them psychologically. Sometimes it is assumed that it causes burnout in managers as a source of stress. On the one hand, the concerned health managers carry out the service by trying to serve people with impaired health. On the other hand, they try to maintain a delicate balance occurred with the participation of the personnel, who are disabled or have a disabled relative, to the service process.

The concept of disability is used together with the concepts of handicap, inadequacy, injury and impairment. The concept is highly relevant to inadequacy and injury. The concept of injury is a temporary or permanent loss of functions of an individual. The concept of inadequacy, on the other hand, is expressed by the inadequacy of the individual in the face of the problems encountered in sustaining his / her life after an injury (Baş, 2016). 
The most general definition of burnout is the exhaustion of energy, power or resources due to strong demand, the feeling of fatigue and failure. It is the mental and physical energy deprivation caused by the constant stress sources of work (Dalkılıç, 2014). For the first time in 1974, Freudenberger used the burnout syndrome in the literature as a result of his research on health employees. According to this research, burnout is defined as the abandonment of job as a result of fatigue and frustration seen in health employees (Gündüz, 2017).

With this study, it is aimed to determine whether the emotion states of health managers in the management of the disabled personnel and their relatives have resulted in burnout. In healthcare organizations, the personnel who are disabled or have disabled relative are employed in polyclinics since they cannot work on night shifts. Starting from this point of view, the research was conducted with the personnel in charge of polyclinic and the assistants. In the context of phenomenological study design, semi-structured interview technique questions were prepared and interviews were conducted. The interview form consisted of two sub-categories following the main study question. In the first part, there were questions that reveal the demographic characteristics of policlinic managers. In the second part, there was a main question including the emotional states and strategies of the health managers during the management of the personnel who are disabled and have a disabled relative, and there were open-ended questions consisted of sub-groups of the main question. When the literature is evaluated, it is seen that the field related to the management of the personnel who are disabled and have a disabled relative is empty. The employee who are disabled or have a disabled relative is not be able to have the same emotional state and thought with a healthy employee. Management of the personnel in this group requires specialty. The research conducted is unique. Therefore, it is thought to be beneficial to add the concept of disability management to the field of organizational behavior and management and organization.

The research is a qualitative study to determine whether a burnout situation occurs in the policlinic managers considering their emotions and states during the management of the personnel who are disabled and have a disabled relative. Phenomenological method model was used in the 
study. Phenomenological method is phenomenology that reveals the phenomena which we lived in but don't understand deeply (Kurubacak, 2017 'den akt. Urgan vd., 2018). The population of the study consisted of health managers working in public hospitals in Eskişehir. The personnel in charge of polyclinic and the assistants were chosen as the sample group since they were directly responsible of the management of the personnel who are disabled or have a disabled relative. For this purpose, 7 health employees, who were in the category, of all public hospitals of the province were interviewed. There are 293 nurses and health officers who provide polyclinic services in all public hospitals in Eskişehir. 51 of them are disabled or have a disabled relative. A semi-structured interview technique sample was prepared for the study and addressed to the participants. In the research, the data analysis was carried out with content analysis from qualitative data analysis. In the content analysis, the data obtained from the interviewers were decoded. A concept was tried to be formed by generalizing the decoded data (Yıldırım ve Şimşek, 2006).

With the study, the relationship between the management of the personnel who are disabled or have a disabled relative and the self-affecting levels of the health managers was tried to be revealed. When interviews and semi-structured interview questions were evaluated, it was found that managers mostly retain their emotional state in the management of personnel with disabilities and disabled relatives. However, it was seen that two managers had a state of burnout. Another outcome of the study is that health managers try to empathize with the personnel who are disabled or have a disabled relative in the management process. Also, the average half of the managers adopt a strategy to perform the procedure in a professional manner by being business oriented.

There are no sufficient studies in the literature on the management of personnel who are disabled or have a disabled relative. In addition, one of the studies included the study group teaching at a special education school. In this study, it was found out that teachers who provide education to students show signs of emotional exhaustion and depersonalization (Şahin ve Şahin, 2012). Burnout and depersonalization were observed in both male and female teachers who teach students with mental disabilities. However, it was found to be higher in male teachers. In the same study, emotional exhaustion and depersonalization scores of teachers who 
were not appreciated by their superiors were found to be higher than those of teachers who were appreciated (Girgin ve Baysal, 2005). The finding that in-service training makes a difference in the perception of burnout level and quality of work of disabled and elderly care personnel is the result of another study (Başol ve Sağlam, 2018).

The personnel who are disabled and have disabled relatives are employed in a significant part of working life. For future studies, performing studies regarding the management of the disabled in different samples and groups will make it easier to understand the subject from a different perspective. This subject is considered as an important issue that should be included in the literature within the scope of the management of the disabled.

\section{Kaynakça / References}

Akdoğan, A. A., İşbir, E. G., Beydoğan, B., Yelsalı Parmaksız, P. M., Sabuktay, A. ve Vural, H. S. (2010). Özürlülüğe dayalı ayrımcılı̆̆ın ölçülmesi araştırması. Ankara: Başbakanlık Özürlüler İdaresi Başkanlı̆̆g.

Arı, G. S. ve Bal, E. Ç. (2008). Tükenmişlik kavramı: Birey ve örgütler açısından önemi. Yönetim ve Ekonomi, 15(1), 131-148.

Başol, O. ve Sağlam, Y. (2018). Engelli ve yaşlı bakım personelinin tükenmişlik seviyeleri ile çalışma yaşam kalitesi algısı ilişkisi. Toplum ve Sosyal Hizmet, 29(2), 71-97.

Baş, M. (2016). Engelli turizmi. Ankara: Nobel.

Burcu, E. (2007). Türkiye'de özürlü birey olma: Temel sosyolojik özellikleri ve sorunları üzerine bir araştırma. Ankara: Hacettepe Üniversitesi Yayınları.

Burcu, E. (2015). Engellilik sosyolojisi. Ankara: Anı Yayıncılık

Çam, O. M. ve Ergin, E. (2017). Hemşirelikte tükenmişlik. Uluslararası Sosyal Araştırmalar Dergisi, 10(51), 501-507.

Dalkılıç, O. S. (2014). Çalışma hayatında tükenmişlik sendromu. Ankara: Nobel.

Erdoğan, P. ve İraz, R. (2019). Örgütsel vatandaşlık, örgütsel sinizme ve tükenmişliğe pozitif psikolojik sermaye etkisi. Konya: Eğitim. 
Erdugan, F. E. (2010). Türkiye'de özürlü yoksulluğu ve mücadele politikalarmın değerlendirilmesi: Ankara-Keçiören Örneği. Ankara: T.C, Başbakanlık, Özürlüler İdaresi Başkanlığı, Yayın No: 50.

Eriş, H., Havlioğlu, S., Küçüközkan, Y., ve Özmen, S. (2017), Suriyeli mülteci kamplarının bulunduğu ilçelerde çalışan hemşire ve ebelerin tükenmişlik seviyesi: Şanlıurfa örneği. Uluslararası Sağlık Yönetimi ve Stratejileri Araştırma Dergisi, 3(3), 326-339.

Girgin, G. ve Baysal, A. (2005). Tükenmişlik sendromuna bir örnek: Zihinsel engelli öğrencilere eğitim veren öğretmenlerin mesleki tükenmişlik düzeyi. TSK Koruyucu Hekimlik Bülteni, 4(4), 172-187.

Gündüz, Ş. (2017). Iş̧ yerinde yaşanan sendromlar. İstanbul: Beta.

Gürbüz, S. ve Şahin, F. (2014). Sosyal bilimlerde araştırma yöntemleri. Ankara: Seçkin.

Kökten, E. ve Erdoğan, B. (2014). Engelli gençler, sosyal dışlanma ve internet. İstanbul: Gelişim Üniversitesi Yayınları.

Krippendorff, K. (2004). Content analysis an introduction to its methodology. California: Sage Publications, Thousand Oaks.

Kurubacak, G. (2017). Nitel araştırmalar ve fenemonoloji. Anadolu Üniversitesi Açıöğretim Sistemi Bilimsel Etkinlikler Semineri. 28.01.2018 tarihinde www.acikbilim.anadolu.edu.tr/seminerler adresinden ulaşıldı.

Maslach, C., Jackson, S. E. ve Leiter, M.P. (1996). MBI: The Maslach burnout inventory: Manual. CA: Consulting Psychologists Press, Palo Alto,

Leiter, M. P. ve Maslach, C. (1988). The impact of interpersonal environment on burnout and organizational commitment. Journal of Organizational Behavior, 9, 297-308.

Özgüven, İ. E. (2016). Endüstri Psikolojisi. Ankara: Nobel.

Potter, W. J. ve Levine-Donnerstein, D. (1999). Rethinking validity and reliability in content analysis. Journal of Applied Communication Research, 27(3), 258-284.

Riggio, R. E. (2014). Endüstri ve örgüt psikolojisine giriş. (L. W. Porter Ed.). (B. Özkara Çev. Ed.), Ankara: Nobel.

Sağlık-Sen Sendikası (2012). Türkiye'de sağlık çalışanları tükenmişlik araştırması sonuçları. Sağlık ve sosyal hizmet çalışanları sendikası raporu. 19.04.2019 tarihinde http://www.saglikcalisanisagligi.org/tezler2/tukenmislikarastirmasi adresinden erişildi. 
Sandıkçı, E. (2017), Sağlık çalışanlarında tükenmişliği önleyici bireysel müdahaleler. Sağlık Çalışanlarının Sağlığı 6. Ulusal Kongresi, 21-22 Ekim 2017, Ankara.

Schaufeli, W. B., Leiter, M. P. ve Maslach, C. (2009). Burnout: 35 years of research and practice. Career Development International, 14(3), 204220.

Solmuş, T. (2004). İş yaşamında duygular ve kişilerarası ilişkiler. İstanbul: Beta Şahin, F. ve Şahin, D. (2012). Engelli bireylerle çalışan özel eğitim öğretmenlerinin tükenmişlik düzeyinin belirlenmesi. Öğretmen Ĕ̆itimi ve Ĕ̆itimcileri Dergisi, 1(2), 275-294.

Thomas, C. (2011). Sakatlık çalı̧̧maları, sosyal bilimlerden bakmak. (D. Bezmez, S. Yardımcı ve Y. Şentürk Der.), (F. B. Aydar Çev.). İstanbul: Koç Üniversitesi Yayınları.

Urgan, S., Sevim, Ş. ve Giderler, C. (2018). Sosyal sermayede sadakat unsurunun kuyumcular ve oto tamircileri bağlamında incelenmesi. Girişimcilik ve Kalkınma Dergisi, Özel Sayı, 123-127.

Usta, H. (1992). Bedensel özürlü olmanın sebepleri. İstanbul: Milli Eğitim Basımevi

Yelpaze, İ. ve Türküm, A. S. (2018). Adaptation and validation of Turkey version of multidimensional attitudes toward persons with disabilities. OPUS-Uluslararası Toplum Araştırmaları Dergisi, 8(14), 167187. DOI: 10.26466/opus.377906

Yıldırım, A.İ. ve Şimşek, H. (2006). Sosyal bilimlerde nicel araştırma yöntemleri. (Güncelleştirilmiş Genişletilmiş 5. Baskı), Ankara: Seçkin.

\section{Kaynakça Bilgisi / Citation Information}

Urgan, S. (2019). Engelli yönetimi ile tükenmişlik arasındaki ilişkiye yönelik sağlık yöneticilerinde yapılan bir araştırma.OPUSUluslararası Toplum Araştırmaları Dergisi, 12(18. UİK Özel Sayısı), 684-702. DOI: $10.26466 /$ opus.585061 